\title{
PROCESS - ORIENTED ARCHITECTUREEFFECT OF A DESIGN METHODOLOGY ON OUTCOMES OF ARCHITECTURE STUDENTS
}

\author{
NAJEH MOHAMmed MOHAMmed \\ Dept. of Architecture, College of Engineering, University of Duhok, Kurdistan Region-Iraq
}

\begin{abstract}
The research presents a comparative investigation of two teaching approaches for architectural design studio: process oriented verse product driven. The processes oriented approach can be defined as a series of actions or steps that are directed toward a specific aim, while product driven is an approach that sets the form of end product as the main guidance for design processes. The research aims at answering the key question of whether the process oriented approach leads to better learning outcomes for architecture students than the product driven one. The study will investigate outputs of design exercises from several architectural design studios at the department of architecture, which are applying either of the two approaches independently. The attempt is to examine the research hypothesis that the process oriented design can be a successful teaching methodology in any architectural department regardless the academic context of the department.
\end{abstract}

KEY WORDS: Process oriented, Product driven, Design process

\section{INTRODUCTION}

$\mathbf{P}$ rocess oriented and product-driven are two different teaching approaches in design studio. Matthew Frederick (2007) listed several points in order to recognize between the two approaches. He cited that "Being process-oriented, not product driven, is the most important and difficult skill for a designer to develop.

Process oriented approach focuses on the thought processes that aim at determining a best design solution for the problem in hand, rather than aiming at the end product or form of design. As Bryan Lawson (2005) mentioned, the design as a process "cannot have a finite and identifiable end. The designer's job is never really done and it is probably always possible to do better". Process means design output is an inevitable result that necessarily generates from the input data, and there are many in-between steps that connect both inputs and outputs and the process never ends. "Processes rarely have fixed beginnings or endings. You can almost always add steps upstream or downstream." (Brennan, T. 1990). Process oriented approach consists of cycles of thinking and drawing process over and over (https://designthesis.wordpress.com/). It implies going through all the right designing processes, and not relying on shortcuts toward the form of the design.

Researchers have investigated the role of both approaches in different areas of teaching. For example, in writing, process oriented focuses on how ideas are developed and formulated (http://www.csuchico.edu/). It considers writing as an approach that goes through a sequence of steps. First it starts with ideas as a draft, then it checks whether the writing is clear to the reader, and the process followed by reflecting new ideas to the first draft, and the cycle continues. While the product driven concerns the forms of the written products that students compose, it deals with the sentence and paragraph organization, or in other word, the form of the sentence or paragraph.

To investigate the quality teaching principles, Sozio, G. et al (2015) used the process oriented verse product oriented worked examples to assist teachers in critiquing the elements of quality teaching. Brooks, C.D. (2009) has shown that process-oriented worked examples, which present a step-by-step solution, lead to improved performance on problem solving and learner attitude in domains such as mathematics and economics.

The purpose of this study is to investigate the effectiveness of two different strategies, process 
oriented and product driven on the quality of students' outcome in the field of architectural design. the key question is whether the process oriented approach leads to better learning outcomes for architecture students than the product driven one. It throws light on how applying these two different designing approaches by students in design studio affect the quality of their projects. It is hoped that the research will help improving quality of teaching by adopting the successful teaching methodology in any architectural department.

\section{Research Survey}

To assess whether students are taught or adopt either approach; process oriented or product driven, a questionnaire was designed for this purpose, the survey was conducted among the students of Architecture, University of Duhok, in the $1^{\text {st }}$ semester of the academic year 2016-2017. Students from four stages (2nd, 3rd, 4th, and 5th stage) of the department were subject to the test. The $1^{\text {st }}$ stage was excluded from the survey. The questionnaire consists of 13 questions, and every student has to select one out of two answers for each question.

Most of the questions are based on (Matthew Frederick, 2007) model that an architecture student should follow in order to be a process oriented rather a product driven. The questionnaire answers were grouped under two sections: A: indicates that a student adopts a process-oriented approach, while B: indicates that a student adopts a product-driven approach. The questionnaire model to investigate whether students adopt either of the two designing model is designed as shown in table (1).

87 out of 110 students responded to the questionnaire. The aim of study findings is to examine how a designing approach adopted by the students is correlated with their project designing results. The final projects marks (teachers assessments of projects) is considered as an indicator for the quality of (how good is) students designing

Table (1): a questionnaire model used to examine students' designing strategy

\begin{tabular}{clll} 
Q. No. & Design Process & A: Process-Oriented approach & B: Product-Driven approach \\
\hline 1 & When exposed to a new program & I seek to understand a design problem & I chase after best solutions \\
2 & As I start a new design & I seek new solutions & I use old solutions for new problems \\
3 & While thinking about concept & I slowly fall in love with ideas & I get very proud of my ideas \\
4 & I make my design decisions & Holistically & Sequentially \\
5 & I make my design decisions & Conditionally & Firmly \\
6 & In the middle of designing & I may change my previous decisions & I stick to my previous decision \\
7 & In the middle of designing & I accept anxiety and uncertainty & anxiety is never accepted \\
8 & As I develop my design & I move from general to specific & work between concept-scale \& detail- \\
9 & I am always concerned about & How my concept works & What my concept looks like \\
10 & If teacher doesn't accept concept & I easily change and start from scratch & I strongly defend my concept \\
11 & In the middle of designing & I am concerned about finding solutions & I am concerned about solving problems \\
12 & As I get to final stage & I hardly feel I am done & I can decide where to stop \\
13 & After a comprehensive investigation & I end up with multiple solutions & I go straight to the final result
\end{tabular}




\section{Data Review And Findings}

The calculation of students' answers in the four stages, (figure 1: a, b, c, \& d), shows that process-

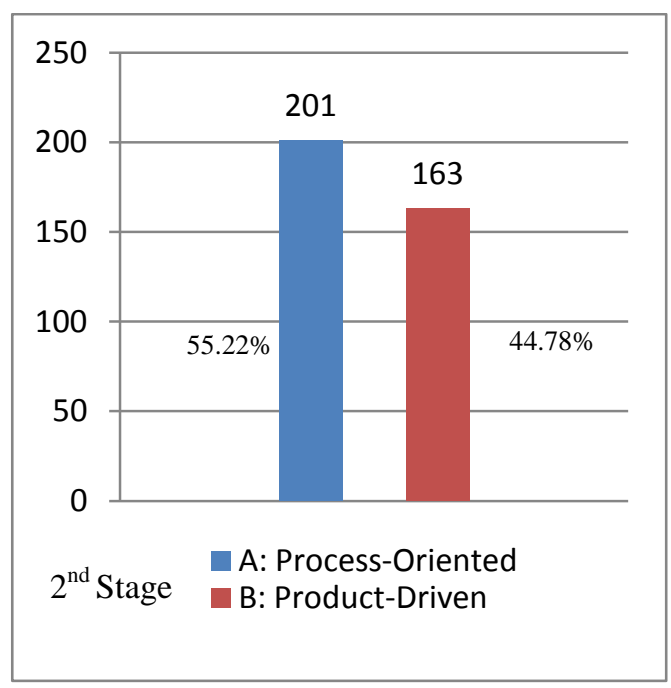

A: students' answers, $2^{\text {nd }}$ stage

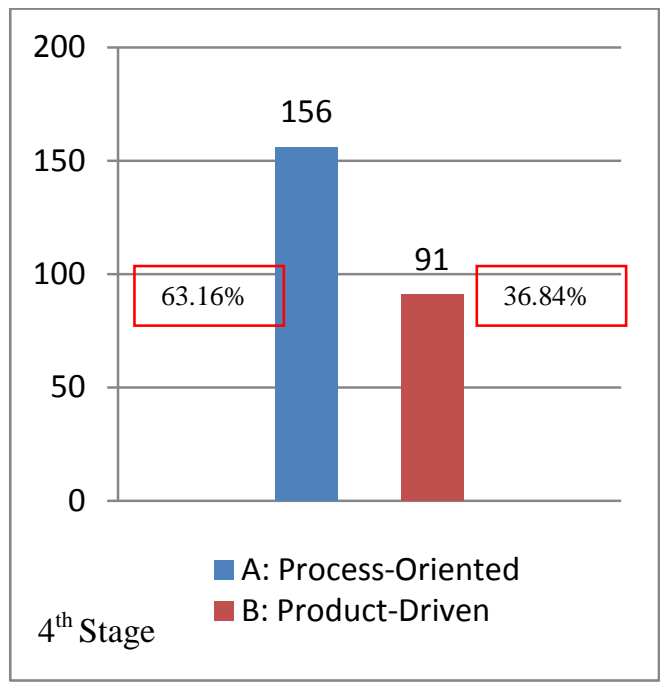

C: students' answers, $4^{\text {th }}$ stage oriented as a designing strategy is more likely adopted among students than product-driven, although the difference between the two approaches, came with variant percentages from one stage to other. Findings also show that most difference in students result came from students of the $4^{\text {th }}$ stage, $63.16 \%$ for process-oriented against $36.84 \%$ for product oriented.

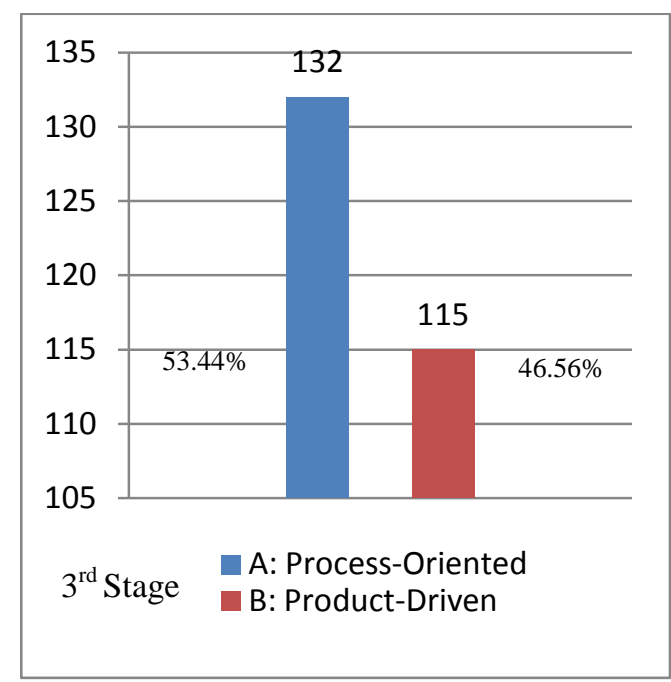

B: students' answers, $3^{\text {rd }}$ stage

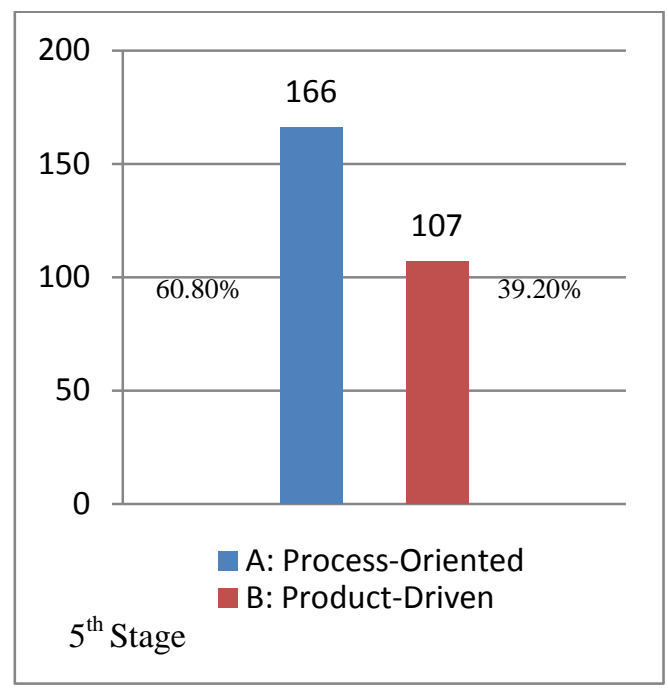

D: students' answers, $5^{\text {th }}$ stage

Fig. (2, A, B, C,\& D): Calculation of students' answers

Answers from the $5^{\text {th }}$ stage also show a close value. The results of the four stages individually also confirmed by the overall results. Figure (3) shows the total results of all students together. The 


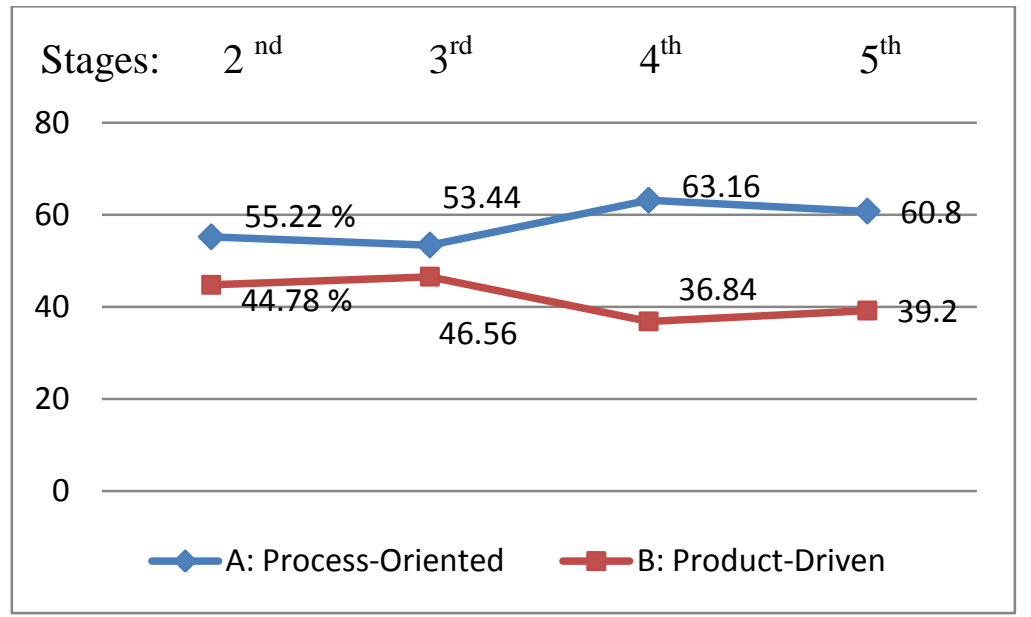

Fig. (2): Calculation of students' answers in the four stages

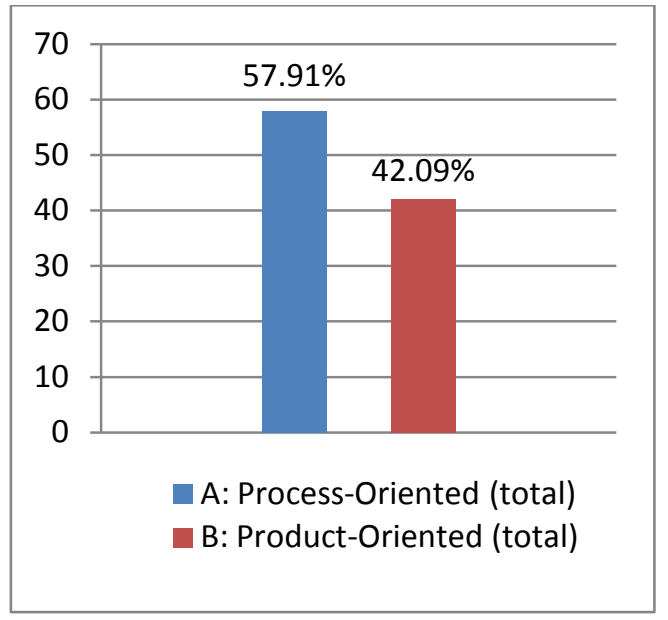

Fig. (3): the overall students' answers
The next step is to test if the findings of the designing process have any link with students designing results of end-semester projects. Table (2) shows first, there is no significance correlation between designing process and students' results, second, in contrary to what the research has hypothesized, the findings of product-driven as a designing approach are more linked to students' result than those of process-oriented approach, although the correlation value is low in all stages. The highest correlation value with product-driven aspect is shown in the $3^{\text {rd }}$ stage, $(\mathrm{R}=0.385)$. The correlation for the overall answers (total) also shows no significance value in either aspect of designing approach.

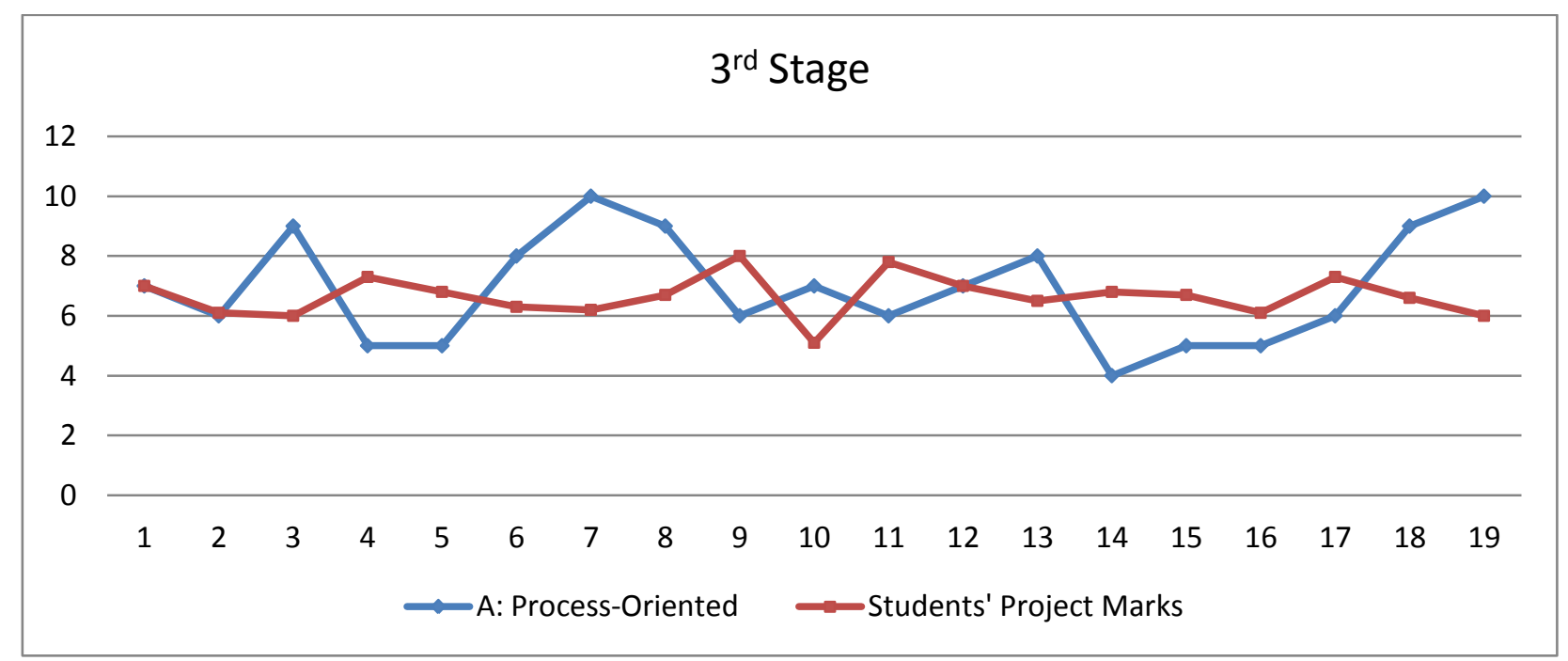

Fig. $(4, A)$ : Correlation between process-oriented approach and students design outputs 


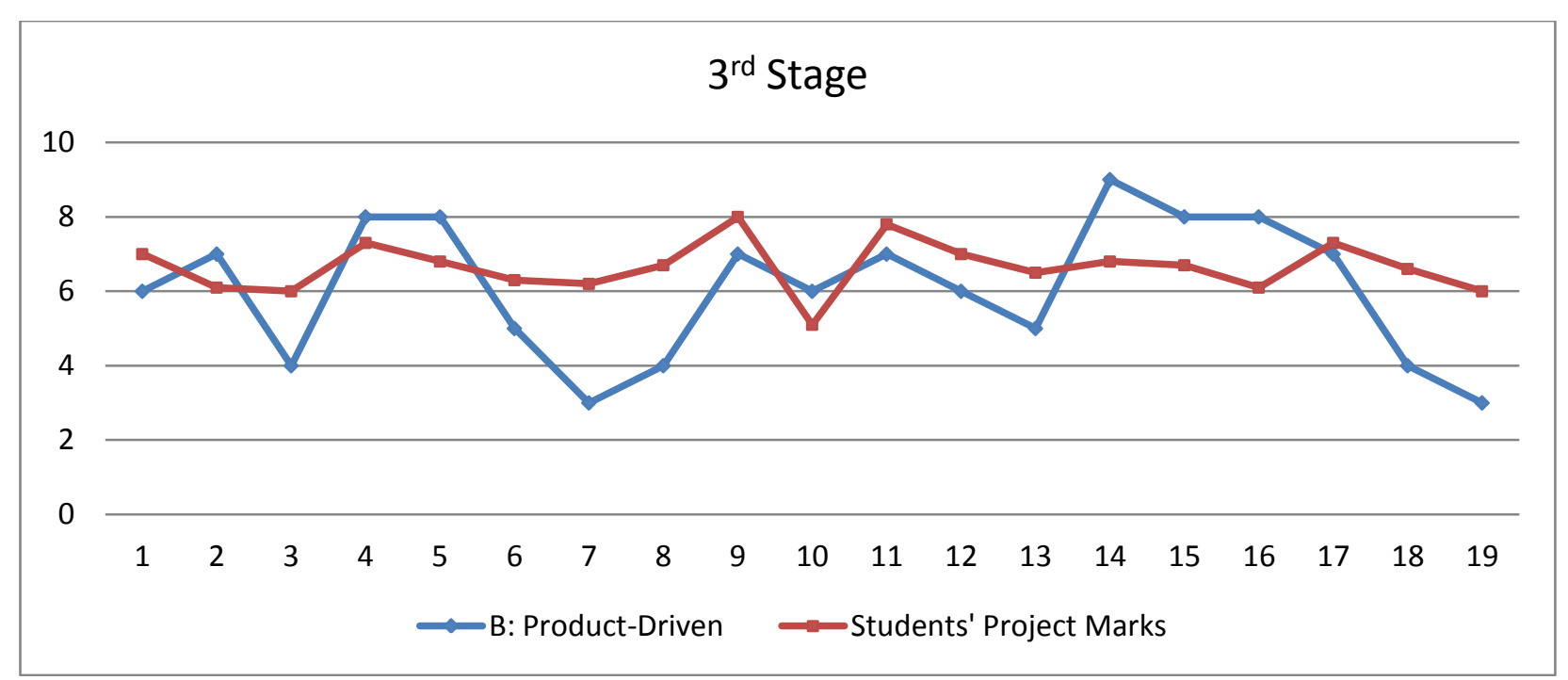

Fig. (4, B): Correlation between product-driven approach and students design outputs

Table (2): Correlation Coefficient between designing approach and students design outputs

\begin{tabular}{ccc}
\hline Stage & Process Oriented & Product Driven \\
\hline $2^{\text {nd }}$ & -0.304 & 0.304 \\
\hline $3^{\text {rd }}$ & -0.385 & 0.385 \\
\hline $4^{\text {th }}$ & -0.149 & 0.149 \\
\hline $5^{\text {th }}$ & -0.065 & 0.074 \\
\hline Total & -0.154 & 0.159 \\
\hline
\end{tabular}

The $3^{\text {rd }}$ set of findings is shown in figure (5), the percentage of each characteristic included within students' designing strategy. The results show five characteristics with significantly high values. They were variant between both process and product approaches. For example, in question no. 3, a high result counted for answer A: I slowly fall in love with my ideas $(68.97 \%)$, which is a process-oriented aspect, rather than B: I get very proud of my ideas. While in question no. 10, a high result counted for answer B: I strongly defend my concept $(70.11 \%)$, which is a productdriven aspect, rather than A: I can easily change my concept.

The interesting result in question no. 9, showed that students in their designing process are much more concerned about what their design/ project looks like $(81.61 \%)$, rather than how their design works. It indicates that they pay a great attention to the shape and exterior form of design instead of how project functions. 


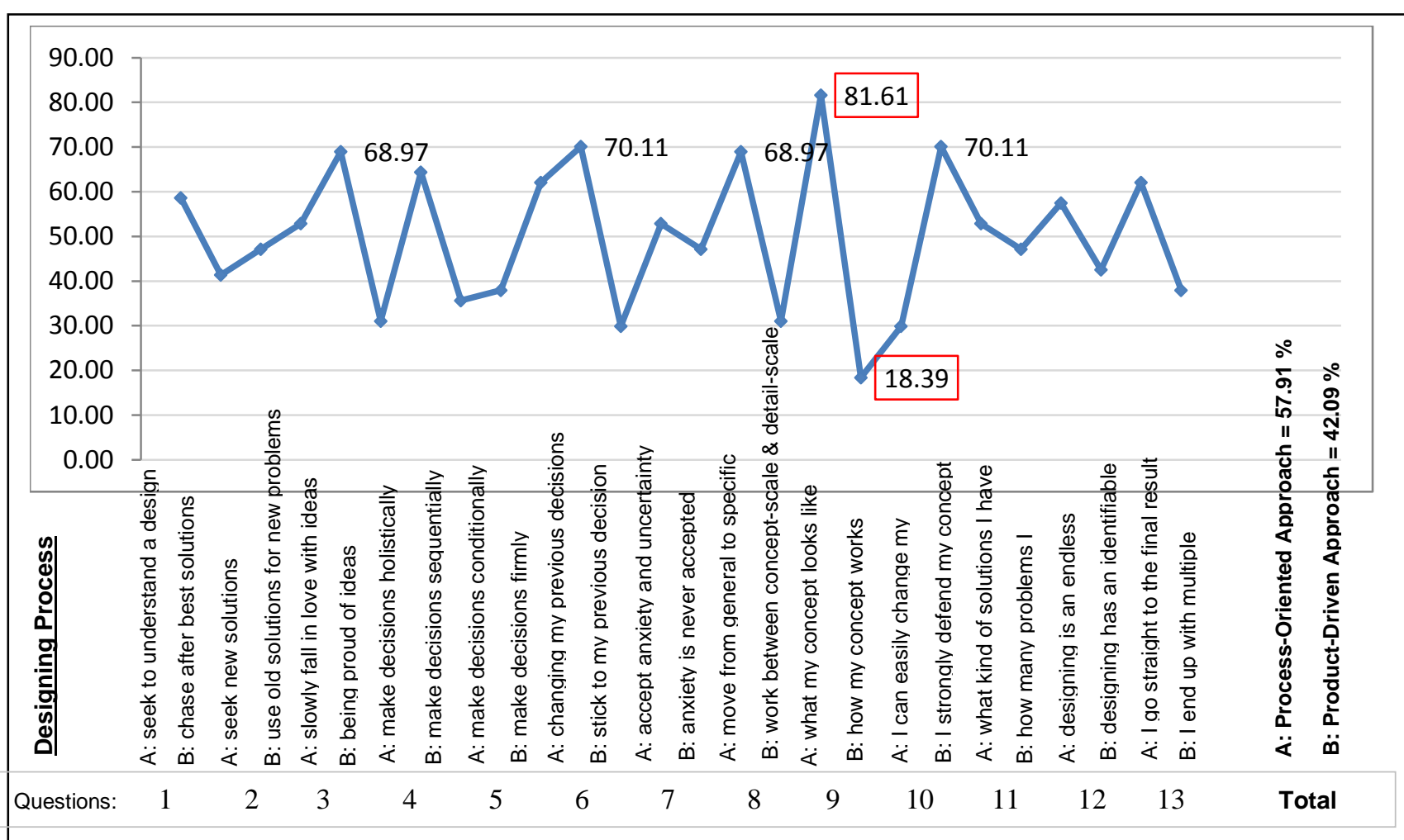

Fig. (5): the designing process aspects included in the questionnaire

\section{CONCLUSION}

The research has reviewed and described two different sources of data, how they were obtained and compiled within the areas of investigation. The research aimed at shading lights on two designing approaches can be adopted as a basic design strategy by architecture students or taught in design studio by teachers. The key question was, either of the two strategies has better learning outcomes, based on assessments of design outputs.

A couple of points can be concluded from the statistical tests revealed by the analysis. First, process-oriented as a designing strategy is more likely adopted among students than productdriven. Second, no significant correlation value was found between students' designing strategy and their design outputs. Third, the study showed that students have adopted (consciously or unconsciously) different designing strategies, and the results were variant among students from different stages. Finally, some aspects of designing process showed that some students have set the form of end product as the main guidance for their designing processes, other aspects showed that some process-oriented aspects also have a considerable presence in students' thoughts of designing.

\section{REFERENCES}

1. Brennan, T. 1990, Design Process, (cited in Dubberly, H., How Do You Design? ), Dubberly Design Office, 2501, Harrison Street, \#7, San Francisco, CA 94110.

2. Brooks, C.D, 2009, Effects of Process-Oriented and Product-Oriented Worked Examples and Prior Knowledge on Learner Problem Solving and Attitude: A study in the domain of microeconomics. Unpublished doctoral dissertation. The Florida State University College of Education.

3. Frederick, M., 2007, 101 Things I Learned in Architecture School, the MIT press Cambridge, Massachusetts London, England.

4. Lawson, B., 2005, How Designers Think, The Design Process Demystified, Architectural Press is an imprint of Elsevier, Linacre House, Jordan Hill, Oxford OX2 8DP, 30 Corporate Drive, Suite 400, Burlington, MA 01803.

5. Sozio, G., et al, 2015, Investigating ProductOriented Versus Process-Oriented Worked Examples to Support Understanding of Quality Teaching Principles, Faculty of Social Sciences, University of Wollongong. 
Journal of University of Duhok, Vol. 20, No.1 (Pure and Eng. Sciences), Pp 1-6, 2017

elSSN: 2521-4861 \& pISSN: 1812-7568

https:// doi.org/10.26682/sjuod.2017.20.1.1

6. https://designthesis.wordpress.com/2008/01/03/proc ess-vs-product/
7. http://www.csuchico.edu/ gthurgood/232/process_a nd_product.pdf 